\title{
Silencing of hTERT blocks growth and migration of anaplastic thyroid cancer cells
}

\author{
Valentina Maggisano a , Marilena Celano a , Giovanni Enrico Lombardo a, \\ Saverio Massimo Lepore a, Marialuisa Sponziello b, Francesca Rosignolo b, \\ Antonella Verrienti ${ }^{b}$, Federica Baldan ${ }^{c}$, Efisio Puxeddu ${ }^{\mathrm{d}}$, Cosimo Durante ${ }^{\mathrm{b}}$, \\ Sebastiano Filetti ${ }^{\mathrm{b}}$, Giuseppe Damante ${ }^{\mathrm{c}}$, Diego Russo ${ }^{\mathrm{a},{ }^{*},}$, Stefania Bulotta ${ }^{\mathrm{a}}$ \\ a Department of Health Sciences, “Magna Graecia” University of Catanzaro, 88100 Catanzaro, Italy \\ ${ }^{\mathrm{b}}$ Department of Internal Medicine and Medical Specialties, "Sapienza" University of Rome, 00161 Rome, Italy \\ ${ }^{\mathrm{c}}$ Department of Medical Area, University of Udine, 33100 Udine, Italy \\ ${ }^{\mathrm{d}}$ Department of Medicine, University of Perugia, 06100 Perugia, Italy
}

\section{A R T I C L E I N F O}

\section{Article history:}

Received 2 August 2016

Received in revised form

9 February 2017

Accepted 7 March 2017

Available online 10 March 2017

\section{Keywords:}

Thyroid cancer

Telomerase

SiRNA

Growth inhibition

Migration

Invasion

\begin{abstract}
A B S T R A C T
Mutations in the $h T E R T$ promoter responsible for constitutive telomerase activity are the most frequent genetic alteration detected in anaplastic thyroid cancer (ATC), and proposed as diagnostic and prognostic biomarker in these tumours. In this study we analyzed hTERT expression in a series of human ATCs and investigated the effects of small-interfering RNA-mediated silencing of $h T E R T$ on viability and migration and invasive properties of three human ATC cell lines. Expression of $h T E R T$ mRNA resulted increased in 8/ 10 ATCs compared to normal thyroid tissues. Silencing of hTERT in CAL-62, 8505C and SW1736 cells did not modify telomere length but determined a significant decrease (about $50 \%$ ) of cell proliferation in all cell lines and a great reduction (about 50\%) of migration and invasion capacity. These finding demonstrate that hTERT may be considered as a molecular target for ATC treatment.
\end{abstract}

() 2017 Elsevier B.V. All rights reserved.

\section{Introduction}

Telomerase reverse transcriptase (TERT) is a catalytic subunit of telomerase, a ribonucleoprotein polymerase acting in maintenance of telomere length at the end of chromosomes, which plays a key role in cellular immortality and tumorigenesis. In normal somatic cells, repressed activity of telomerase is associated with a progressive shortening of telomeres, which leads to growth arrest. In contrast, it is constitutively active in several cancer cells in which permits telomeres maintenance and unlimited cellular proliferation (Skvortzov et al., 2009; Liu and Xing, 2016). Interestingly, a

Abbreviations: ATA, American Thyroid Association; ATC, anaplastic thyroid carcinoma; FF, fresh-frozen thyroid tumour tissues; FFPE, formalin-fixed paraffinembedded thyroid tumour sections; FNAB, fine needle aspiration biopsy; TERT, telomerase reverse transcriptase.

* Corresponding author. Department of Health Sciences, University "Magna Graecia" of Catanzaro, Campus "S. Venuta”, Viale Europa, 88100 Catanzaro, Italy.

E-mail address: d.russo@unicz.it (D. Russo). correlation between hTERT mRNA expression and telomerase activity has been described in cancer cells of various origin (Toshikuni et al., 2000; Kirkpatrick et al., 2003; Zhang et al., 2006a).

In tumour cells, telomerase activation may be due to hTERT gene amplification, engagement of TERT alternative splicing or somatic mutations in the hTERT promoter (Skvortzov et al., 2009). The latter ones have been described as the most frequent genetic alterations of anaplastic thyroid cancer (ATC), the most aggressive histotype of thyroid neoplasms (Liu et al., 2013). In these tumours, as in the majority of human neoplasia, the frequent cytosine-to-thymine transition in the $h T E R T$ promoter determines an activation of hTERT transcriptional activity in cancer cells (Horn et al., 2013; Liu et al., 2013; Killela et al., 2013). An overexpression of hTERT has recently been described in a series of thyroid tumours, which included also some lymph node metastatic tissues, but not ATCs (Muzza et al., 2015).

Silencing hTERT to inhibit the telomerase activity and cell proliferation of cancer cells has successfully been adopted in some experimental models of cancer, as hepatocellular, breast and 
cervical cancer cells (Mo et al., 2003; Natarajan et al., 2004; Zhang et al., 2006a, 2006b; de Souza Nascimento et al., 2006; Dong et al., 2009). In this study, we analyzed hTERT mRNA expression in a series of human ATC and investigated the effects of small-interfering RNA-mediated silencing of hTERT on the viability, migration, and invasive properties of three human anaplastic thyroid cancer cell lines harboring (8505C and SW1736 cells) or not (CAL-62 cells) a mutation in hTERT promoter.

\section{Materials and methods}

\subsection{Collection of thyroid tissues}

Ten patients with ATC have been enrolled at the "Sapienza" University Hospital of Rome (Italy) $(n=5)$ and at University Hospital of Perugia (Italy) $(n=5)$. Fresh-frozen thyroid tumour tissues (FF) and formalin-fixed paraffin-embedded (FFPE) thyroid tumour sections have been collected in each centre, respectively. Eighteen thyroid adjacent non-tumour tissues (i.e. nine FF thyroid biopsy specimens and nine FFPE thyroid samples) from patients subjected to total thyroidectomy for sporadic thyroid cancer at the "Sapienza" University Hospital of Rome were collected. Samples were selected for a tumour sample cellularity more than $60 \%$ and for absence of signs of inflammation or other types of disease in the normal thyroid tissues. Clinical data were collected by retrospective review of hospital charts and tumours were classified according to the American Joint Committee on Cancer TNM staging system (Table 1). The study was approved by the local medical ethics committee.

\subsection{Extraction of RNA and gene expression studies}

TRIzol reagent was used for RNA isolation from FF tissues and thyroid cell lines (Thermo Fisher Scientific Inc., Waltham, MA, USA) (Sponziello et al., 2016). Recover All Total Nucleic Acid Isolation Kit (Thermo Fisher Scientific Inc.) was used for RNA isolation from FFPE thyroid tissue specimens. cDNA synthesis was performed with High Capacity cDNA Reverse Transcription kit (Thermo Fisher Scientific Inc.) from $1 \mu \mathrm{g}$ of total RNA. mRNA levels of $h T E R T$ were assessed in thyroid tissues and cell lines by real time PCR on a 7900 HT Fast Real-time PCR System (Thermo Fisher Scientific Inc.) following standard procedures. Data analyses were carried out using SDS 2.4 software (Thermo Fisher Scientific Inc.). Final results were determined by the comparative $2^{-\Delta \Delta \mathrm{ct}}$ method using beta- 2 microglobulin (tissues) or beta-actin (cell lines) as endogenous control, and shown as relative expression normalized to a calibrator sample group (adjacent non-tumour thyroid tissues from FF or FFPE samples and Nthy-ori-3-1 cells).

Table 1

Clinical Characteristics of ATC patients.

\begin{tabular}{lllllllll}
\hline$\#$ & Sex & Age at diagnosis & $\mathrm{T}$ & $\mathrm{N}$ & $\mathrm{M}^{*}$ & STAGE & BRAF & TERT \\
\hline 1 & $\mathrm{M}$ & 61 & $4 \mathrm{~b}$ & $1 \mathrm{~b}$ & 0 & IVb & WT & C228T \\
2 & $\mathrm{M}$ & 69 & $4 \mathrm{~b}$ & 1 & $\mathrm{x}$ & IVb & WT & C228T \\
3 & $\mathrm{~F}$ & 65 & $4 \mathrm{~b}$ & $1 \mathrm{~b}$ & $\mathrm{x}$ & IVb & WT & WT \\
4 & $\mathrm{M}$ & 31 & $4 \mathrm{~b}$ & 1 & 0 & IVb & WT & WT \\
5 & $\mathrm{~F}$ & 35 & $4 \mathrm{~b}$ & 0 & 1 & IVc & WT & WT \\
6 & $\mathrm{M}$ & 87 & $4 \mathrm{~b}$ & $1 \mathrm{~b}$ & $\mathrm{x}$ & IVb & WT & WT \\
7 & $\mathrm{~F}$ & 72 & $4 \mathrm{~b}$ & 0 & 1 & IVc & WT & C228T \\
8 & $\mathrm{M}$ & 31 & $4 \mathrm{~b}$ & 0 & 0 & IVb & WT & WT \\
9 & $\mathrm{M}$ & 74 & NA & NA & NA & NA & WT & C228T \\
10 & $\mathrm{M}$ & 78 & $4 \mathrm{~b}$ & $1 \mathrm{~b}^{*}$ & $\mathrm{x}$ & IVb & V600E & C228T
\end{tabular}

Abbreviations F, female; $M$, male; $M^{*}$, metastase; $N$, node; NA, not available; $T$, tumour; WT, wild type.

\subsection{Thyroid cell lines and hTERT silencing}

In this study, we used three human anaplastic thyroid carcinoma cell lines: $8505 C$ and SW1736, characterized by the presence of BRAFV600E mutation as well as C250T and C253T (for 8505C) or C228T (for SW1736) mutations of hTERT promoter, and CAL-62, which does not bear either BRAFV600E or hTERT promoter mutation (Schweppe et al., 2008; Liu et al., 2013; Jeon et al., 2016). As control, we used the non-tumorigenic Nthy-ori-3-1 cells (Sponziello et al., 2016). Short Tandem Repeat analysis was performed to check the genomic stability of these cell lines. Cells were cultured in RPMI or DMEM (Thermo Fisher Scientific Inc.) medium at $37{ }^{\circ} \mathrm{C}$ in a humidified $5 \% \mathrm{CO}_{2}$ as previously described (Celano et al., 2015; Sponziello et al., 2016). Three different hTERT-specific SiRNA (sihTERT) (sequences $5^{\prime}$ to $3^{\prime}$ : a. AGGCACUGUUCAGCGUGCUCAACUA; b. GCCUGUUUCUGGAUUUGCAGGUGAA c. CCUCUGUGCUGGGCCUGGACGAUAU were transiently transfected into cells using lipofectamine RNAiMAX (Thermo Fisher Scientific Inc.), following the manufacturer's instructions. Briefly, cells were plated in 6 well plates $\left(130 \times 10^{3} /\right.$ well $)$ and the next day, when the cells had reached $60-80 \%$ confluence, the medium was replaced with fresh medium with siRNA hTERTa, b, or c. After further $4 \mathrm{~h}$, the medium was replaced again with fresh medium. After $48 \mathrm{~h}$, transfection efficiency was evaluated by RT-PCR and western blot assays. In all experiments, control is indicated as siCtrl and represents cells transfected with Stealth RNAi Negative Control Duplexes (Thermo Fisher Scientific Inc.).

\subsection{DNA extraction and telomere length assay}

After hTERT silencing, genomic DNA of 8505C, CAL-62 and SW1736 cells was isolated by the Gentra Puregene Cell Kit (Qiagen, Hilden, Germany), according to the manufacturer protocol. The mean telomere length was evaluated by using the TeloTAGGG Telomere Length Assay kit (Hoffmann-La Roche Ltd, Basel, Switzerland). Briefly, $2 \mu \mathrm{g}$ of genomic DNA were digested with restriction enzymes Hinfl and Rasl for $2 \mathrm{~h}$ at $37^{\circ} \mathrm{C}$ and then separated on $0.8 \%(\mathrm{w} / \mathrm{v})$ agarose gel. The DNA fragments were capillary transferred to a positively charged nitrocellulose membrane (GE Healthcare, Little Chalfont, United Kingdom) in 20x saline-sodium citrate buffer overnight at room temperature. After UVcrosslinking, the membrane was hybridized with a DIG-labeled probe specific for telomeric repeats and incubated with a DIGantibody coupled to alkaline phosphatase. The signal was detected using a highly sensitive chemiluminescent substrate CDP-star. Telomere length was calculated using the UVITEC Alliance LD (UVITec Limited, Cambridge, United Kingdom) with the SuperSignal Technology (Thermo Fisher Scientific Inc.). The calculation of mean TRF length was defined as mean TRF $=\sum(\mathrm{ODi}) / \sum(\mathrm{ODi} / \mathrm{Li})$ where ODi is the chemiluminescent signals and $\mathrm{Li}$ is the length of TRF at position $\mathrm{i}$.

\subsection{Protein extraction and western blot analysis}

Total proteins were extracted as previously described (Maggisano et al., 2014). Twenty-five $\mu \mathrm{g}$ of total protein extracts were run on a $9 \%$ or $12 \%$ SDS-PAGE gel and transferred to PVDF membrane (VWR, Milan, Italy), blocked with TTBS/milk (TBS, 1\% Tween 20 and 5\% non-fat dry milk) and incubated overnight with affinity-purified anti-TERT (Abcam, Cambridge, United Kingdom) and anti-GAPDH antibodies (Thermo Fisher Scientific Inc.), diluted $1: 1000$ and $1: 50,000$, respectively. The membranes were incubated with horseradish peroxidase-conjugated anti-rabbit or anti-mouse antibody (Transduction Laboratories, Lexington, KY, USA) in TTBS/ milk, diluted $1: 5000$ or $1: 50,000$ respectively. Western blot 
detection system ECL Plus (Perkin Elmer, Monza, Italy) was used to visualize the proteins.

\subsection{Analysis of cell proliferation and cell cycle}

Cell growth of 8505C, CAL-62 and SW1736 was evaluated by MTT assay and cell count (Celano et al., 2015). $48 \mathrm{~h}$ after hTERT silencing performed with sihTERTa, for MTT assay cells were seeded in 96 well plates at a density of $3.5 \times 10^{3}$ and after 24,48 and $72 \mathrm{~h}$, the solubilized product was quantified with a microplate spectrophotometer (xMark, Biorad, Milan, Italy) at a wavelength of $540 \mathrm{~nm}$ and a reference wavelength of $690 \mathrm{~nm}$; for cell count assay, cells, seeded in 12 well plates $60 \times 10^{3}$ for well, were counted in the hematocytometric chamber. Results are expressed as percentages over control (siCtrl), represented by cells transfected with Stealth RNAi Negative Control Duplexes (Thermo Fisher Scientific). Trypan blue dye exclusion assay was used to evaluate cell viability after hTERT silencing as previously described (Bulotta et al., 2013).

\section{TERT wild type $\square T E R T$ C228T $\square T E R T \mathrm{C} 228 \mathrm{~T}+B R A F \mathrm{~V} 600 \mathrm{E}$}

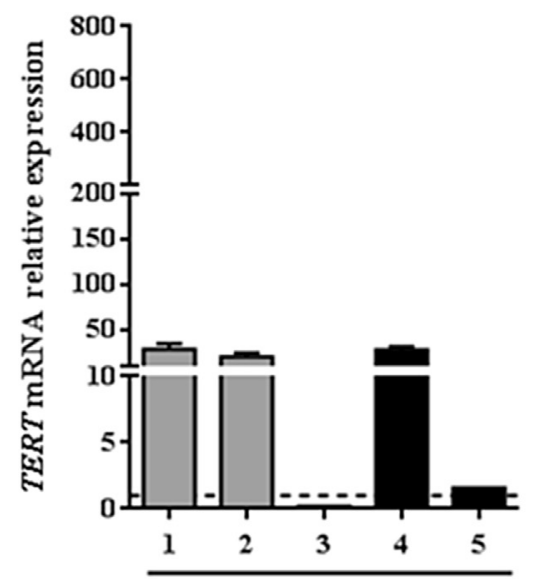

FFPE - ATC

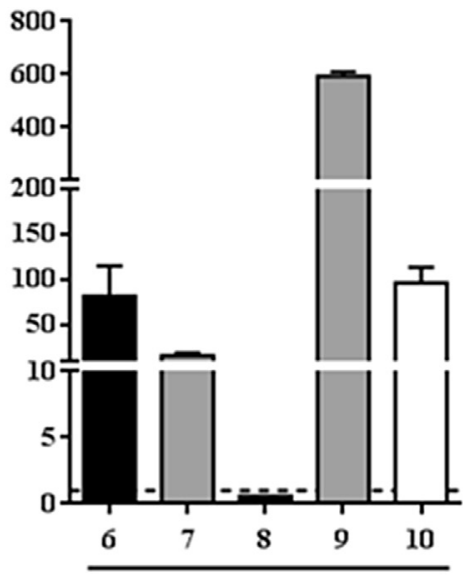

FF - ATC

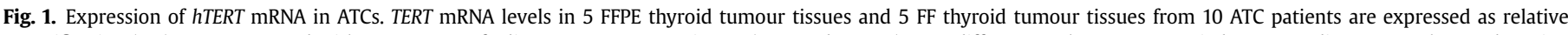

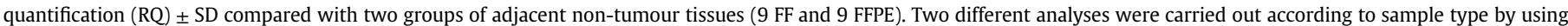

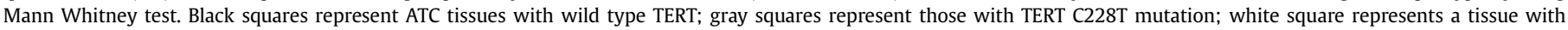
BRAFV600E and TERT C228T mutations. FF, fresh-frozen thyroid tumour tissues; FFPE, formalin-fixed paraffin-embedded thyroid tumour sections.
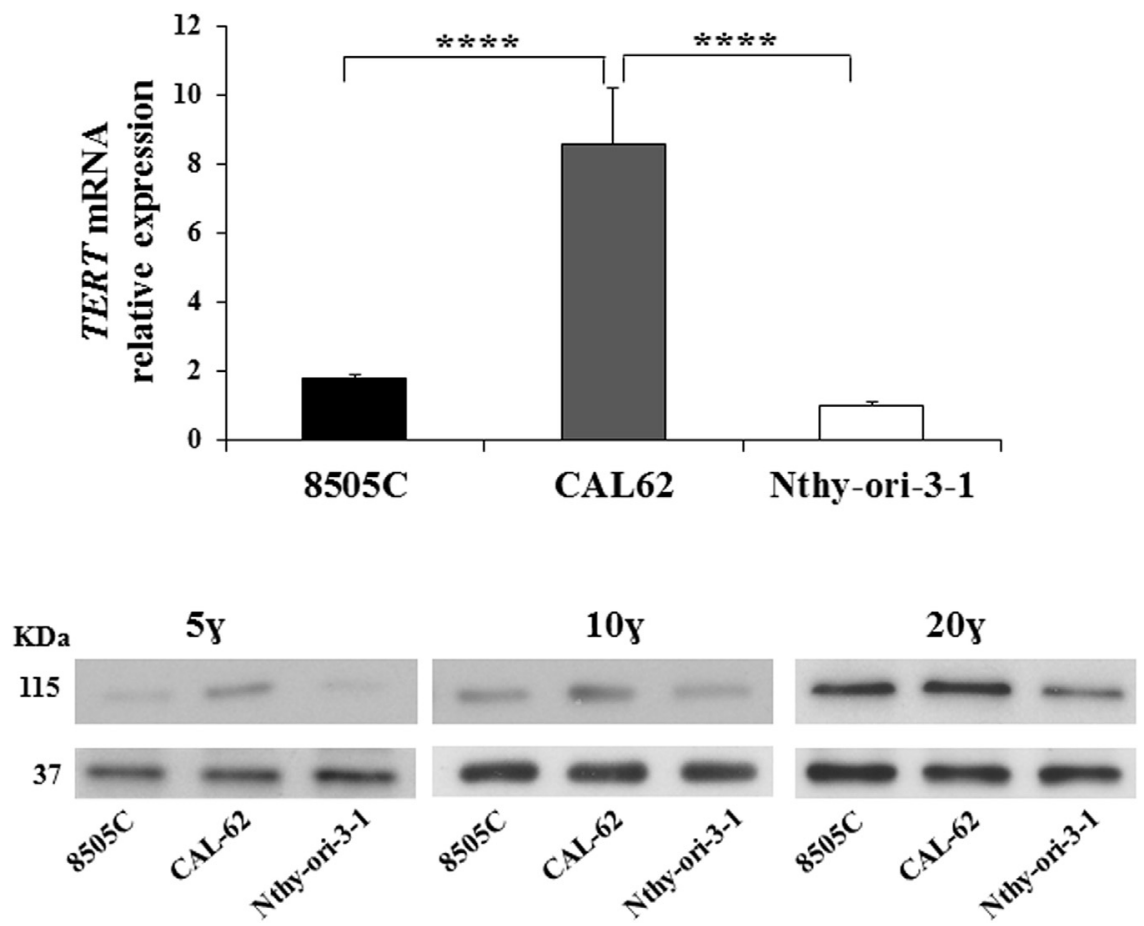

TERT

\section{GAPDH}

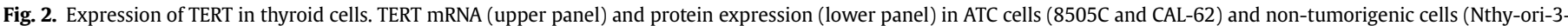

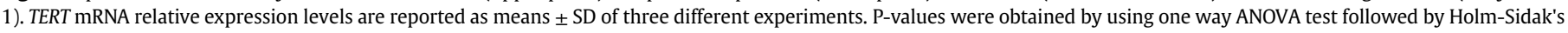
multiple comparisons test. ${ }^{* * *} \mathrm{p}<0.0001$. One representative of three western blot experiments showing TERT protein, as described in Materials and Methods, is shown. 
For cell cycle analysis, $48 \mathrm{~h}$ after $h T E R T$ silencing, cells were harvested and fixed in $70 \%$ cold ethanol at $-20^{\circ} \mathrm{C}$ overnight. Then, were washed and incubated with PBS containing $0.1 \%$ Triton X-100, $20 \mu \mathrm{g} / \mathrm{ml}$ propidium iodide and $0.05 \mu \mathrm{g} / \mathrm{ml}$ RNaseA for $30 \mathrm{~min}$ at $37^{\circ} \mathrm{C}$. The stained cells were analyzed using a FAC Scan laser flow cytometer equipped with Cell Quest software (Becton Dickinson, San Jose, CA, USA).

\subsection{Annexin V-FITC/PI staining}

For apoptosis assay, Annexin V-FITC/PI staining was performed according to the kit manufacturer's instructions (Miltenyil Biotech, Bologna, Italy). Forty-eight hours after hTERT silencing with sihTERT a, $1 \times 10^{6}$ cells were plated and after $24 \mathrm{~h}$, were detached by trypsin, centrifuged and washed with $1 \mathrm{x}$ binding buffer. Cell pellet was suspended in $1 \mathrm{x}$ binding buffer and $10 \mu \mathrm{l}$ of Annexin V-FITC were added. The samples were incubated for $15 \mathrm{~min}$ in the dark at room temperature and then washed with $1 \mathrm{x}$ binding buffer. Cell pellet was suspended in $1 \mathrm{x}$ binding buffer and $5 \mu \mathrm{l}$ of PI were added immediately prior to analysis by flow cytometry using FAC Scan laser flow cytometer equipped with Cell Quest software (Becton Dickinson).

\subsection{Migration and invasion assays}

Transwell inserts with $8 \mu \mathrm{m}$ pore were used for cell migration assay (Costar, Euroclone, Milan, Italy). The same inserts coated with matrigel (Becton Dickinson) were adopted for invasion assay. Fortyeight hours after hTERT silencing performed with sihTERT a, $60 \times 10^{3}$ cells suspended in serum-free medium containing $1 \%$ BSA (for migration assay) or 1\% FBS (for invasion detection), were plated in the upper chamber of the inserts. As chemiotactic agent in the bottom wells were added $600 \mu \mathrm{l}$ of medium containing $10 \%$ FBS. After 6 or $24 \mathrm{~h}$ of incubation (for detection of migration and invasion, respectively), not migrated cells were removed with cotton swabs from the upper surface of the filters which were fixed and stained with Diff-Quick Stain (Bio Map, Monza, Italy). Finally, cells were counted using a microscope provided with an eyepiece and equipped with a counting grid. Results from the count of five random fields are expressed as percentages over siCtrl.

\subsection{Statistical analysis}

Data of cell proliferation, migration and invasion experiments were analyzed by one-way ANOVA followed by the Tukey-Kramer multiple comparisons test. Intergroup differences in the expression of hTERT mRNA levels were assessed with Mann Whitney test and Holm-Sidak's multiple comparisons test in tissue samples and cell lines, respectively. All results are expressed as mean \pm standard deviation (SD) and were considered statistically significant pvalues lower than 0.05 . All statistical analyses were performed using GraphPad Prism version 5.0 statistical software (GraphPad Software Inc., San Diego, CA, USA).

\section{Results}

3.1. Expression levels of hTERT in thyroid tumour tissues and cancer cell lines

We first analyzed the expression levels of hTERT in 10 ATCs characterized for the presence of BRAFV600E or hTERT promoter mutation (Table 1) by using real-time RT-PCR. We observed that hTERT transcript levels were significantly higher than those of a series of normal tissues in 8 out of 10 tumours (Fig. 1). The lowest levels of hTERT were found in two ATCs negative for the promoter mutations. Higher levels of expression of both hTERT mRNA and protein were found also in the ATC cell lines 8505C and CAL-62 compared to those of the non-tumorigenic cell line Nthy-ori-3-1 (Fig. 2).

\subsection{Effects on telomere length, proliferation, migration, and} invasiveness of thyroid cancer cells after siRNA-mediated silencing of hTERT

To check the role of hTERT in ATC cells, we transfected 8505C, CAL-62 and SW1736 cells, an additional ATC cell line hosting $h T E R T$ promoter mutation, with three different and specific hTERT siRNAs (sihTERT a, b, c) (Fig. 3). The strongest decrease in the levels of TERT protein expression was obtained with sihTERTa, which was the only siRNA effective on all three cell lines, in accordance with other studies showing that a limited fraction of designed siRNAs are able of completely silencing hTERT gene in human cancer cells (Xia et al., 2012). Therefore, sihTERT a was used in all the following experiments. When hTERT expression was downregulated, telomere
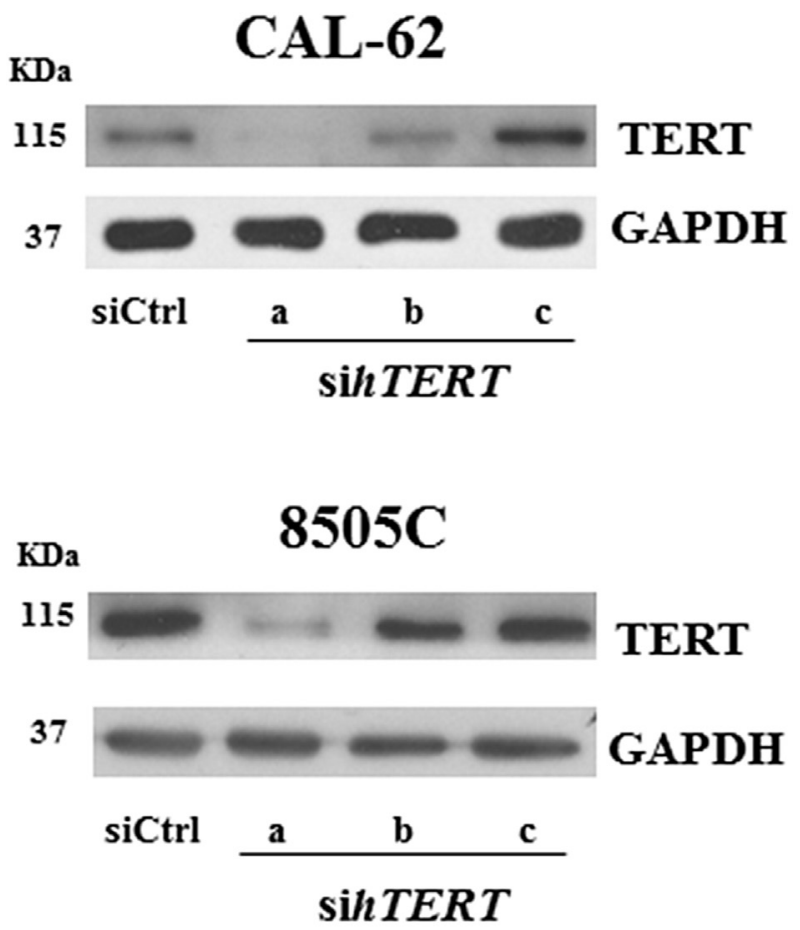

SW1736

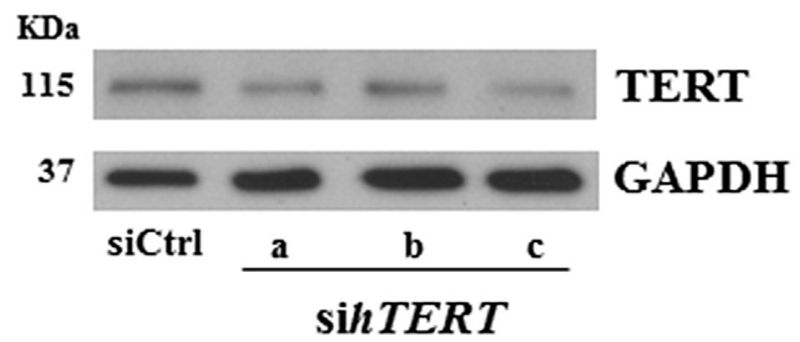

Fig. 3. Silencing of $h T E R T$ in ATC cells. Silencing of $h T E R T$ was performed using three different siRNAs indicated as a, b and c in CAL-62, 8505C and SW1736 cells, as described in Materials and Methods. The picture shows one representative of three western blot experiments for TERT protein and GAPDH which was used as loading control. 
length was controlled. As shown in Supplementary Fig. 1, the three cell lines show different telomere length (lowest in SW1736 and highest in CAL-62) which was not modified after silencing. However, after $48 \mathrm{~h}$ from the start of silencing, cell viability, measured after further 24 h by both MTT assay and cell counting, resulted decreased $\sim 50 \%$ over controls in all cell lines ( $\mathrm{p}<0.001$ vs siCtrl) (Fig. 4). Similar results were noted even examining the cell viability after 48 and $72 \mathrm{~h}$. Significant additional reduction of viability after $72 \mathrm{~h}$, was observed only in CAL-62 ( $\mathrm{p}<0.05$ vs sihTERT a $24 \mathrm{~h}$ ) (Fig. 4). No differences in cell viability were observed by trypan blue assay (data not shown). In hTERT-silenced CAL-62, cytofluorimetric analysis showed a reduction of G0/G1 phase and a block in S phase of the cell cycle (Fig. 5), while in 8505C and SW1736 a mild block in G0/G1 phase was observed. Moreover, annexin V-FITC/PI staining assays (Supplementary Fig. 2) show a slight shift towards increasing fluorescence due to presence of apoptotic cells only in CAL-62 cells. This difference in the FACS profile probably reflects the difference in the properties of the three cell lines, consistent with the highly undifferentiated phenotype of ATCs, maintained also after establishment of cell cultures. Altogether, these data demonstrate that silencing of $h T E R T$ produces a mainly cytostatic effect in ATC cells.

Finally, we checked the effects of silencing of hTERT on the migration and invasive properties of the three cell lines. As shown in Fig. 6, a significant reduction of cell migration ( $60 \%, \mathrm{p}<0.001$, for 8505C and SW1736; 50\%, p $<0.01$, for CAL-62 cell lines), and invasion ( 60\%, p $<0.001$ in $8505 \mathrm{C}$ and CAL-62, 40\%, $\mathrm{p}<0.05$ in SW1736 cell lines) was observed.

\section{Discussion}

Treatment of ATCs represents still a major clinical challenge. Most of patients have a very poor prognosis, mainly because are refractory to radioiodine therapy and poorly responsive to chemo- and radiotherapy, so accounting for approximately a third of the mortality rate caused by thyroid cancer (Smallridge et al., 2009; Smallridge and Copland, 2010; Kojic et al., 2011; Garcia-Rostan et al., 2015). A recent comprehensive genetic characterization of these tumours has revealed some key genetic abnormalities which contribute to their development (Landa et al., 2016). Among them, mutations in hTERT promoter have been detected with high frequency, confirming several previous reports (reviewed in Liu and Xing, 2016), and strengthening the hypothesis of a role of this genetic alteration in determining the aggressive behavior of these neoplasms, especially when co-occurring with RAS/BRAF mutations (Liu and Xing, 2016; Alzahrani et al., 2016; Xu and Ghossein, 2016).

In the last years, there has been an increasing interest concerning the presence and frequency of hTERT mutation in thyroid tumour tissues for their prognostic negative role, due to the oncogenic role attributed to hTERT overexpression. Moreover, search for $h T E R T$ promoter mutations in the materials of FNAB has been suggested and also validated in the screening of suspicious thyroid nodules (Alzahrani et al., 2016). However, other genomic abnormalities have been found in ATCs. Each of them appears in tumour tissues which do not host TERT promoter mutations (Landa et al., 2016).

Gene silencing by using the siRNA approach is today an essential tool to understand the roles of genes in biological functions. Therefore, we tested the effects of hTERT gene silencing in three human ATC cell lines which are widely used as model of aggressive thyroid cancer. Since there are no reports on the expression of hTERT gene in ATC tissues, we first screened a series of these tumours, finding that, independent from the presence or not of the mutations in the promoter, a higher expression of the gene was found in most of the tumour specimens when compared to normal thyroid tissues. In addition, expression of TERT was observed also in three ATC cell lines harboring (8505C and SW1736 cells) or not
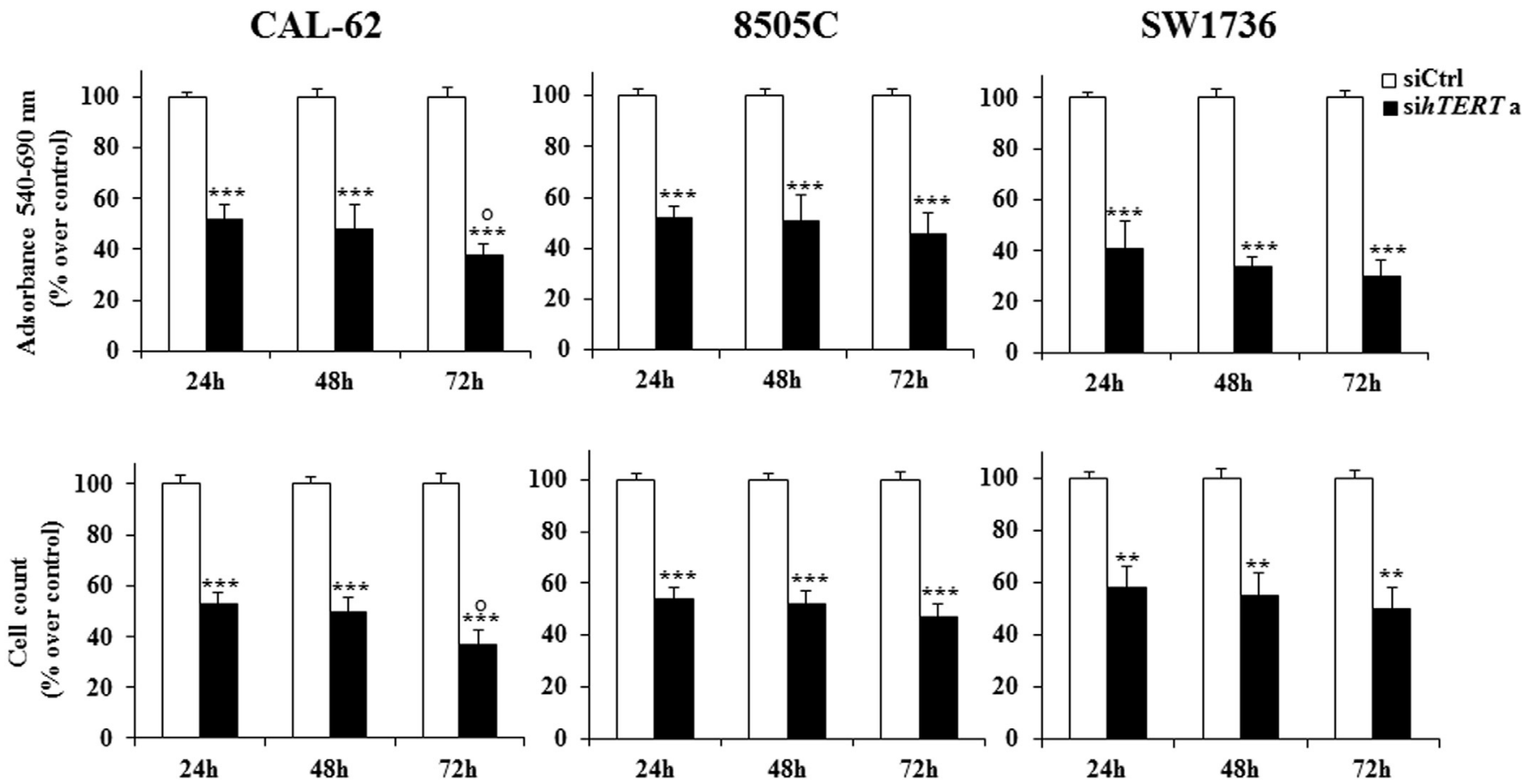

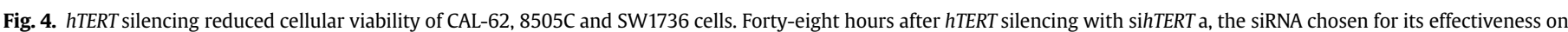

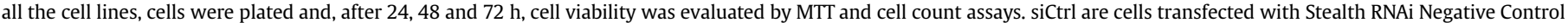

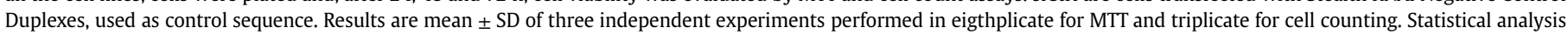
was performed using the Tukey-Kramer multiple comparisons test. ${ }^{* *} \mathrm{p}<0.01,{ }^{* * *} \mathrm{p}<0.001$ vs siCtrl; ${ }^{\circ} \mathrm{p}<0.05$ vs $24 \mathrm{~h}$ sihTERT a. 


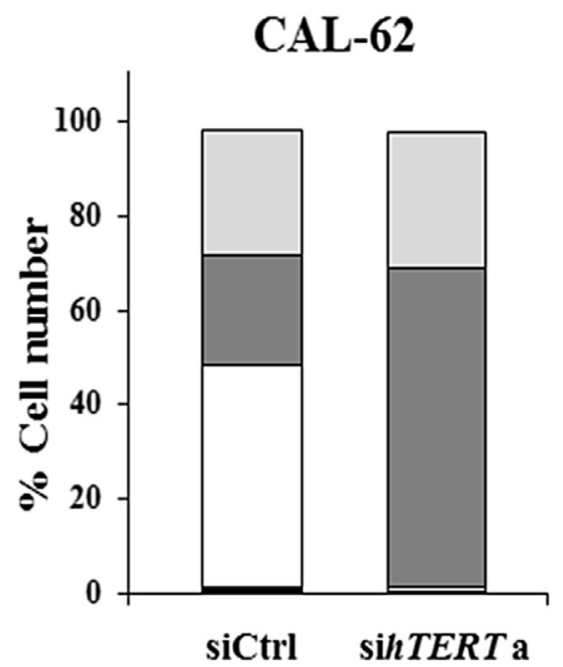

$8505 \mathrm{C}$

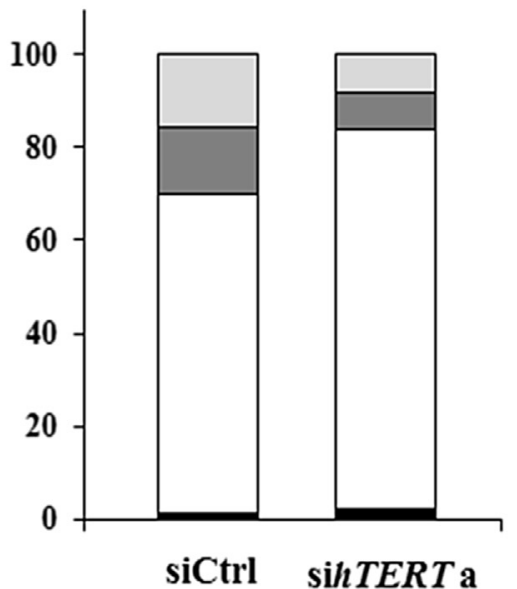

SW1736

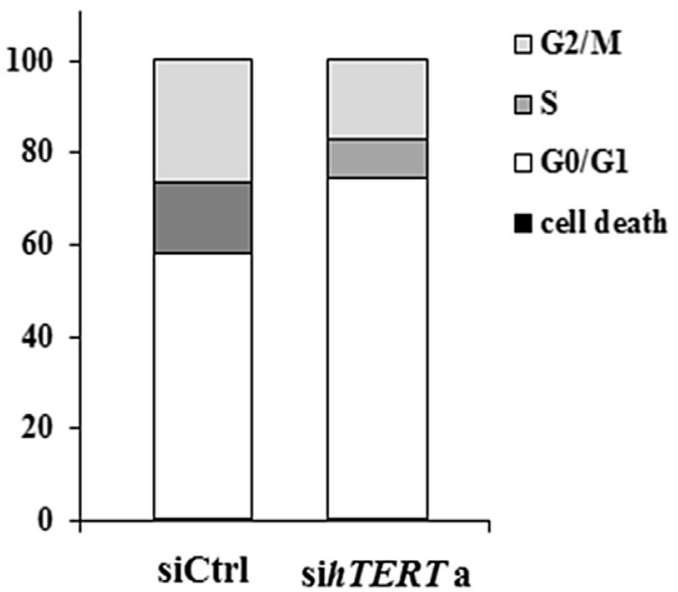

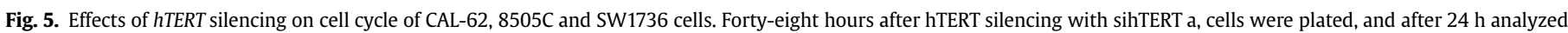

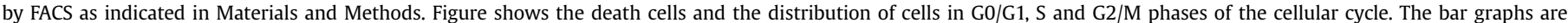
representative of three independent experiments.
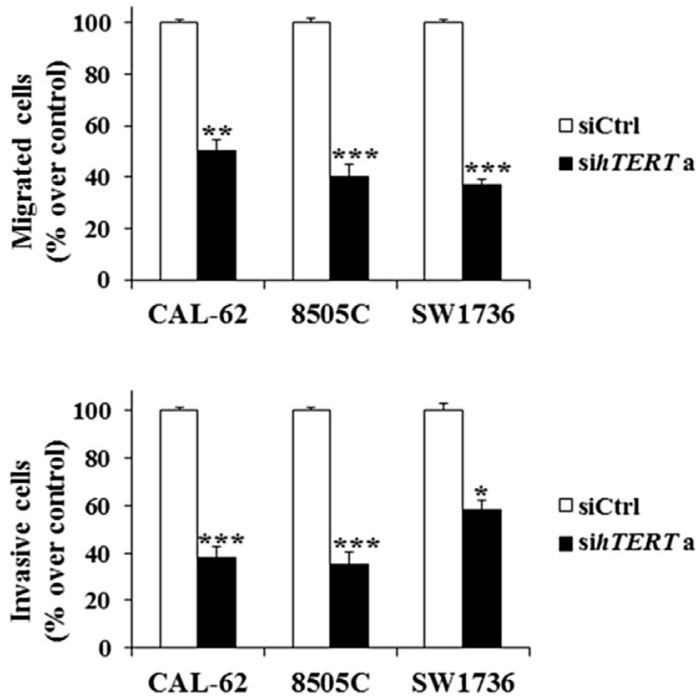

Fig. 6. Effect of hTERT silencing on migration and invasion of CAL-62, 8505C and SW1736 cells. Cells, treated with sihTERT a or Stealth RNAi Negative Control Duplexes used as control sequence ( $\mathrm{iCtrl}$ ), were prepared for migration and invasion assays as indicated in Materials and Methods. For migration and invasion, after 6 and $24 \mathrm{~h}$, respectively, filters were stained, photographed at $10 \times$ magnification, and cells counted. Each experiment was performed in triplicate and values are expressed as mean \pm SD from 2 independent experiments. Statistical analysis was performed using the Tukey-Kramer multiple comparisons test. ${ }^{*} \mathrm{p}<0.05,{ }^{* *} \mathrm{p}<0.01,{ }^{* * *} \mathrm{p}<0.001$ vs siCtrl.

(CAL-62 cells) a mutation in hTERT promoter. This finding confirms that TERT overexpression may occur also in absence of promoter mutations (Skvortzov et al., 2009). All lines (8505C, CAL-62 and SW1736) were then subjected to hTERT silencing to test the role of hTERT in cell proliferation and other parameters of aggressiveness.

Our findings demonstrate that silencing of hTERT, without affecting the telomere length, reduces cell proliferation and causes a decrease in invasion and migration ability of these three ATC cell lines. It cannot be excluded the possibility that the observed decrease in migration upon TERT silencing could partially be due to the inhibition of cell proliferation. Similar results were also obtained by Teng et al., using a permanent transfection of antisense hTERT RNA (Teng et al., 2003). The major function of telomerase is thought to be telomere elongation; however, accumulating evidences indicate that it controls expression of various genes implicated in control of cell proliferation and cancer progression (Smith et al., 2003), proposing that TERT may act as an oncogene in a telomere-independent manner (Liu and Xing, 2016; Wyatt et al., 2010) as seems to occur in ATCs cell lines.

These results were not surprising considering the success of this approach in other models of human cancer. Indeed, the growth of various cancer cells resulted inhibited by TERT silencing, even using non-viral vectors to deliver the siRNA into the cells (Xia et al., 2012; Shi et al., 2014; Xie et al., 2014; Li et al., 2015). Thus, considering our present findings, targeting hTERT may be taken into consideration even against the less differentiated and more aggressive thyroid cancer cells.

As mentioned above, the search for hTERT promoter mutation is now suggested and in some case adopted even in an early diagnostic stage of suspicious thyroid nodules (Liu and Xing, 2014). In consideration of the potential use as therapeutic target, detection of this biomarker, in terms of mRNA expression in FNAB material, may provide useful additional information for approaching those tumours unresponsive to the current treatment. While not routinely recommended for initial postoperative risk stratification (2015 ATA guidelines; Haugen et al., 2016), the mutational analysis of TERT promoter has the potential to refine risk of persistent/recurrent disease when interpreted in the context of other clinico-pathologic risk factors. Our results show that TERT overexpression may occur also in absence of promoter mutations and that silencing of hTERT reduces proliferation, invasion and migration of ATC cell lines. Therefore, we believe that also the evaluation of TERT expression could be useful to predict risk of persistent/recurrent disease. Genetic and epigenetic characterization of a neoplasm is now considered an optimal way toward a personalized and more effective treatment. In fact, it may allow the identification of molecular markers of a particular tumour and, if detected in an early phase of the management of the patients, may offer novel opportunity to improve the outcome of the more aggressive tumours. In this context, our findings demonstrate that $h T E R T$ may represent an optimal candidate to be targeted in the anaplastic thyroid cancer. 


\section{Acknowledgements}

The study was supported by the Fondazione Umberto Di Mario ONLUS and by a grant to GD from Italian Minister of Foreigner Affairs and International Cooperation (MAECI) (Progetti Grande Rilevanza Italia-Serbia ${ }^{\circ}$ PGR00223).

\section{Appendix A. Supplementary data}

Supplementary data related to this article can be found at http:// dx.doi.org/10.1016/j.mce.2017.03.007.

\section{References}

Alzahrani, A., Alsaadi, R., Murugan, A.K., Sadiq, B.B., 2016. TERT promoter mutations in thyroid cancer. Horm. Cancer 7, 165-177.

Bulotta, S., Corradino, R., Celano, M., Maiuolo, J., D'Agostino, M., Oliverio, M., Procopio, A., Filetti, S., Russo, D., 2013. Antioxidant and antigrowth action of peracetylated oleuropein in thyroid cancer cells. J. Mol. Endocrinol. 51, 181-189.

Celano, M., Maggisano, V., De Rose, R.F., Bulotta, S., Maiuolo, J., Navarra, M., Russo, D., 2015. Flavonoid fraction of Citrus reticulata juice reduces proliferation and migration of anaplastic thyroid carcinoma cells. Nutr. Cancer 67 (7), 1183-1190.

de Souza Nascimento, P., Alves, G., Fiedler, W., 2006. Telomerase inhibition by an siRNA directed against hTERT leads to telomere attrition in HT29 cells. Oncol. Rep. 16, 423-428.

Dong, X., Liu, A., Zer, C., Feng, J., Zhen, Z., Yang, M., Zhong, L., 2009. siRNA inhibition of telomerase enhances the anti-cancer effect of doxorubicin in breast cancer cells. BMC Cancer 9, 133.

Garcia-Rostan, G., Tallini, G., Salvatore, G., 2015. Anaplastic thyroid carcinoma: molecular tools for diagnosis and therapy. Int. J. Endocrinol. http://dx.doi.org/ $10.1155 / 2015 / 341725,341725$.

Haugen, B.R., Alexander, E.K., Bible, K.C., Doherty, G., Mandel, S.J., Nikiforov, Y.E., Pacini, F., Randolph, G., Sawka, A., Schlumberger, M., Schuff, K.G., Sherman, S.I., Sosa, J.A., Steward, D., Tuttle, R.M., Wartofsky, L., 2016. 2015 american thyroid association management guidelines for adult patients with thyroid nodules and differentiated thyroid cancer. Thyroid 26, 1-133.

Horn, S., Figl, A., Rachakonda, P.S., Fischer, C., Sucker, A., Gast, A., Kadel, S., Moll, I., Nagore, E., Hemminki, K., Schadendorf, D., Kumar, R., 2013. TERT promoter mutations in familial and sporadic melanoma. Science 339, 959-961.

Jeon, M.J., Kim, W.G., Sim, S., Lim, S., Kwon, H., Kim, T.Y., Shong, Y.K., Kim, W.B., 2016. Low prevalence of somatic TERT promoter mutations in classic papillary thyroid carcinoma. Endocrinol. Metab. 31, 100-104.

Killela, P.J., Reitman, Z.J., Jiao, Y., Bettegowda, C., Agrawal, N., Diaz Jr., L.A., Friedman, A.H., Friedman, H., Gallia, G.L., Giovanella, B.C., Grollman, A.P., He, T.C., He, Y., Hruban, R.H., Jallo, G.I., Mandahl, N., Meeker, A.K., Mertens, F., Netto, G.J., Rasheed, B.A., Riggins, G.J., Rosenquist, T.A., Schiffman, M., Shih, I.M., Theodorescu, D., Torbenson, M.S., Velculescu, V.E., Wang, T.L., Wentzensen, N., Wood, L.D., Zhang, M., McLendon, R.E., Bigner, D.D., Kinzler, K.W., Vogelstein, B., Papadopoulos, N., Yan, H., 2013. TERT promoter mutations occur frequently in gliomas and a subset of tumours derived from cells with low rates of selfrenewal. Proc. Natl. Acad. Sci. U. S. A. 110, 6021-6026.

Kirkpatrick, K.L., Clark, G., Ghilchick, M., Newbold, R.F., Mokbel, K., 2003. hTERT mRNA expression correlates with telomerase activity in human breast cancer. Eur. J. Surg. Oncol. 29, 321-326.

Kojic, S.L., Strugnell, S.S., Wiseman, S.M., 2011. Anaplastic thyroid cancer: a comprehensive review of novel therapy. Exp. Rev. Anticancer Ther. 11, 387-402.

Landa, I., Ibrahimpasic, T., Boucai, L., Sinha, R., Knauf, J.A., Shah, R.H., Dogan, S., Ricarte-Filho, J.C., Krishnamoorthy, G.P., Xu, B., Schultz, N., Berger, M.F., Sander, C., Taylor, B.S., Ghossein, R., Ganly, I., Fagin, J.A., 2016. Genomic and transcriptomic hallmarks of poorly differentiated and anaplastic thyroid cancers. J. Clin. Invest. 126, 1052-1066.

Li, H., He, J., Yi, H., Xiang, G., Chen, K., Fu, B., Yang, Y., Chen, G., 2015. siRNA suppression of hTERT using activatable cell-penetrating peptides in hepatoma cells. Biosci. Rep. 35 http://dx.doi.org/10.1042/BSR20140145.

Liu, R., Xing, M., 2014. Diagnostic and prognostic TERT promoter mutations in thyroid fine-needle aspiration biopsy. Endocr. Rel. Cancer 21, 825-830.

Liu, R., Xing, M., 2016. TERT promoter mutations in thyroid cancer. Endocr. Rel. Cancer 23, R143-R155.

Liu, X., Bishop, J., Shan, Y., Pai, S., Liu, D., Murugan, A.K., Sun, H., El-Naggar, A.K. Xing, M., 2013. Highly prevalent TERT promoter mutations in aggressive thyroid cancers. Endocr. Rel. Cancer 20, 603-610.

Maggisano, V., Puppin, C., Celano, M., D'Agostino, M., Sponziello, M., Micali, S. Navarra, M., Damante, G., Filetti, S., Russo, D., 2014. Cooperation of histone deacetylase inhibitors SAHA and valproic acid in promoting sodium/iodide symporter expression and function in rat Leydig testicular carcinoma cells. Endocrine 45, 148-152.

Mo, Y., Gan, Y., Song, S., Johnston, J., Xiao, X., Wientjes, M.G., Au, J.L., 2003. Simultaneous targeting of telomeres and telomerase as a cancer therapeutic approach. Cancer Res. 63, 579-585.

Muzza, M., Colombo, C., Rossi, S., Tosi, D., Cirello, V., Perrino, M., De Leo, S. Magnani, E., Pignatti, E., Vigo, B., Simoni, M., Bulfamante, G., Vicentini, L., Fugazzola, L., 2015. Telomerase in differentiated thyroid cancer: promoter mutations, expression and localization. Mol. Cell. Endocrinol. 399, 288-295.

Natarajan, S., Chen, Z., Wancewicz, E.V., Monia, B.P., Corey, D.R., 2004. Telomerase reverse transcriptase (hTERT) mRNA and telomerase RNA (hTR) as targets for downregulation of telomerase activity. Oligonucleotides 14, 263-273.

Schweppe, R.E., Klopper, J.P., Korch, C., Puqazhenthi, U., Benezra, M., Knauf, J.A. Fagin, J.A., Marlow, L.A., Copland, J.A., Smallridge, R.C., Haugen, B.R., 2008 Deoxyribonucleic acid profiling analysis of 40 human thyroid cancer cell lines reveals cross-contamination resulting in cell line redundancy and misidentification. J. Clin. Endocrinol. Metab. 93, 4331-4341.

Shi, Y.A., Zhao, Q. Zhang, L.H., Du, W., Wang, X.Y., He, X., Wu, S., Li, Y.L., 2014 Knockdown of hTERT by siRNA inhibits cervicalcancer cell growth in vitro and in vivo. Int. J. Oncol. 45, 1216-1224.

Skvortzov, D.A., Rubzova, M.P., Zvereva, M.E., Kiselev, F.L., Donzova, O.A., 2009. The regulation of telomerase in oncogenesis. Acta Naturae 1,51-67.

Smallridge, R.C., Marlow, L.A., Copland, J.A., 2009. Anaplastic thyroid cancer: molecular pathogenesis and emerging therapies. Endocr. Rel. Cancer 16, 17-44.

Smallridge, R.C., Copland, J.A., 2010. Anaplastic thyroid carcinoma: pathogenesis and emerging therapies. Clin. Oncol. Roy. Coll. Radiol. 22, 486-497.

Smith, L.L., Coller, H.A., Roberts, J.M., 2003. Telomerase modulates expression of growth-controlling genes and enhances cell proliferation. Nat. Cell Biol. 5, 474-479.

Sponziello, M., Rosignolo, F., Celano, M., Maggisano, V., Pecce, V., De Rose, R.F., Lombardo, G.E., Durante, C., Filetti, S., Damante, G., Russo, D., Bulotta, S., 2016 Fibronectin-1 expression is increased in aggressive thyroid cancer and favors the migration and invasion of cancer cells. Mol. Cell. Endocrinol. 431, 123-132.

Teng, L., Specht, M.C., Barden, C.B., Fahey 3rd, T.J., 2003. Antisense hTERT inhibits thyroid cancer cell growth. J. Clin. Endocrinol. Metab. 88, 1362-1366.

Toshikuni, N., Nouso, K., Higashi, T., Nakatsukasa, H., Onishi, T., Kaneyoshi, T. Kobayashi, Y., Kariyama, K., Yamamoto, K., Tsuji, T., 2000. Expression of telomerase associated protein 1 and telomerase reverse transcriptase in hepatocellular carcinoma. Brit. J. Cancer 82, 833-839.

Wyatt, H.D., West, S.C., Beattie, T.L., 2010. In TERT preting telomerase structure and function. Nucleic Acids Res. 38, 5609-5622.

Xia, W., Wang, P., Lin, C., Li, Z., Gao, X., Wang, G., Zhao, X., 2012. Bioreducible polyethylenimine-delivered siRNA targeting human telomerase reverse transcriptase inhibits HepG2 cell growth in vitro and in vivo. J. Control. Rel 157, $427-436$

Xie, Y., Qiao, H., Su, Z., Chen, M., Ping, Q., Sun, M., 2014. PEGylated carboxymethyl chitosan/calcium phosphate hybrid anionic nanoparticles mediated hTERT siRNA delivery for anticancer therapy. Biomaterials 35, 7978-7991.

Xu, B., Ghossein, R., 2016. Genomic landscape of poorly differentiated and anaplastic thyroid carcinoma. Endocr. Pathol. 27 (3), 205-212.

Zhang, P.H., Zou, L., Tu, Z.G., 2006a. RNAi-hTERT inhibition hepatocellular carcinoma cell proliferation via decreasing telomerase activity. J. Surg. Res. 131, 143-149.

Zhang, Y.A., Nemunaitis, J., Samuel, S.K., Chen, P., Shen, Y., Tong, A.W., 2006b. Antitumor activity of an oncolytic adenovirus-delivered oncogene small interfering RNA. Cancer Res. 66, 9736-9743. 